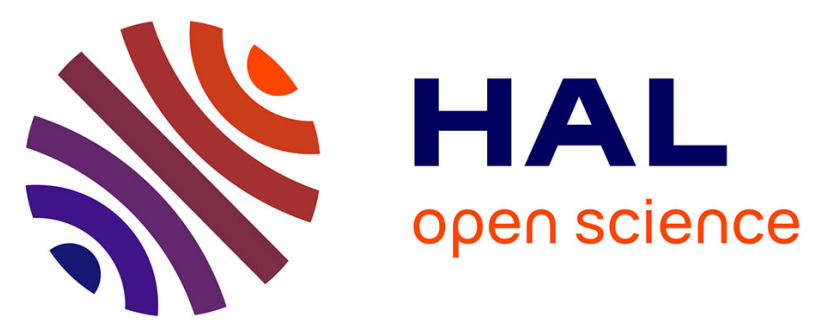

\title{
Case Study on Engineering Change Management and Digital Manufacturing
}

Simo-Pekka Leino, Lauri Jokinen, Juha-Pekka Anttila, Antti Pulkkinen

\section{To cite this version:}

Simo-Pekka Leino, Lauri Jokinen, Juha-Pekka Anttila, Antti Pulkkinen. Case Study on Engineering Change Management and Digital Manufacturing. 12th IFIP International Conference on Product Lifecycle Management (PLM), Oct 2015, Doha, Qatar. pp.591-600, 10.1007/978-3-319-33111-9_53 . hal-01377486

\section{HAL Id: hal-01377486 https://hal.inria.fr/hal-01377486}

Submitted on 7 Oct 2016

HAL is a multi-disciplinary open access archive for the deposit and dissemination of scientific research documents, whether they are published or not. The documents may come from teaching and research institutions in France or abroad, or from public or private research centers.
L'archive ouverte pluridisciplinaire HAL, est destinée au dépôt et à la diffusion de documents scientifiques de niveau recherche, publiés ou non, émanant des établissements d'enseignement et de recherche français ou étrangers, des laboratoires publics ou privés. 


\title{
Case study on Engineering Change Management and Digital Manufacturing
}

\author{
Simo-Pekka Leino ${ }^{1}$, Lauri Jokinen ${ }^{2}$, Juha-Pekka Anttila ${ }^{1}$, Antti Pulkkinen ${ }^{3}$
}

${ }^{1}$ VTT Technical Research Centre of Finland, ${ }^{2}$ Metso Mining and Construction,

${ }^{3}$ Tampere University of Technology

\begin{abstract}
Improved engineering change management (ECM) has been recognized as one of the major gain areas in manufacture. Digital Manufacturing (DM) is proposed as a means for improved ECM. This paper introduces the preliminary findings of a case study in manufacturing industry. The main proposed development targets include: Integrated PLM architecture and processes, parallel product structures, baseline structure for virtual prototypes, richer information model, and re-designed product development process. The results are categorized in the dimensions of internal and external functions, new product development and standard production, corrective changes and betterment, physical and virtual product. The novelty of this paper within PLM research emerges from the nature of business and focused product development processes of the case, because majority of related literature is related to mass production.
\end{abstract}

\section{Introduction}

An effective product development process is vital for corporate success [1,2]. Because the products and value networks are more complicated, companies require a more holistic product lifecycle approach and efficient co-operation across disciplines $[3,4]$. This approach also increases the management of product-related knowledge for product development [1,2]. However, according to [1], in most businesses even $60 \%$ of total operational time does not add value to a product or process, and a major portion of the waste is caused by a lack of efficient knowledge management. The traditional staged product development process model is not flexible enough [5]. Therefore, newer methods, such as concurrent engineering have been adopted in product development. They are based on more flexible processes, information redundancy and anticipated rapid feedback. On the other hand new product development projects face several risks coming from technical, market, budget and schedule dimensions [6]. These risks are normally managed through iterations, i.e. feedback based redesign. Iteration may be [5] 
small including minor changes to components of a product, or large including for instance market feedback that changes the whole design. The more early uncertainty exists, the more engineering changes will probably occur and the more difficult it is to implement the changes during the product development [7].

Inside large iterations minor changes are conducted for instance in productization phase rooted e.g. from identified design errors. Engineering change management (ECM) normally refers to a formal process when product manufacture specifications have been released and need to be modified, and it is usually understood as part of standard production of released products. However, engineering changes occur of course also in new product development (NPD) projects, and these changes are attempted to be managed nowadays with a more formal ECM process. However, there are remarkable differences [8] between the management of engineering changes in engineering design projects and configure-to-order mode. Most requests for changes arise because stakeholders' knowledge has not been integrated into the design process [9]. Fleche et al. argue that the use of collaborative tools, such as digital manufacturing, can reduce the emergent changes in the later NPD phases when it is used early enough.

The objective of this paper is to discuss how virtual prototyping, digital manufacturing (DM) and PLM provide for management of change in proactive engineering design, and to propose generic PLM development targets that have been recognized within the case study. In this paper, DM is defined as wide utilisation of $3 \mathrm{D}$ and other digital product information in concurrent engineering within the frame of PLM.

This paper is structured so that the following section introduces the case study methodology, material and analysis. The section after that discusses the findings and finally the conclusions of the research are summed up.

\section{Case study in a manufacturing company}

The case study started 2013 and is in progress. Methods of the case study included interviews, workshopping, process modelling (internal and external organization functions and suppliers), PLM use scenarios for information modelling, PLM impact analysis [10], and comparison of past and ongoing new product projects and standard production. Nature of the case study is action research, meaning that the aim is on analyzing the present challenges (as-is processes) and changing the situation in the company (to-be processes). Based on the DM pilot studies, the potential benefits and impacts of DM and PLM to different stakeholders as well as to processes and technology have been estimated.

The case company has a strategic goal of reduced time-to-market and time-toprofit in new product development (NPD), and better overall profitability of manufacturing. The products of the case company are typically partially configurable variants for mining business, which mean that in practice almost every product individual is different. This kind of variant production paradigm with relatively low 
production volumes requires high flexibility of the production system, hence the involvement of human actors and manual work.

The case company is simultaneously re-designing their new product development function and defining new processes. Earlier there used to be a separate internal productization function for building prototypes and preparing new products for standard production. However, in future new products will be launched straight to the standard production line in order to boost ramp-up and learning curve. Obviously, this causes challenges for the product design and development, organisation and management, supporting processes and product data management; because new products must be more mature.

Improved ECM has been recognized as a major gain area. Thus, ECM is also the driver for implementing DM as one of the proposed means for reaching the business goals. When the new products are launched and ramped-up straight to standard production, the design and product structures should be more mature, but also the material flows and assembly tasks should be well planned.

Analysis of the case material. Generally speaking, analysis of the case material concluded that engineering change requests and modifications are made too late in NPD projects. Obviously, this is a common problem in industry. However, in this project aim is to find out what can be done in order to decrease engineering changes in late project phases, and thus decrease time-to-market and time-toprofit. The NPD project should be frontloaded by transferring late corrective changes towards early proactive and improving changes.

Traditionally, generation of engineering requests begin with the first physical prototype, but lot of changes are requested later in the ramp-up and even in standard production phase. However, source of the change request vary depending the change. Similarly, prioritization of engineering change requests varies as well. For instance, engineering changes can be categorized as corrective changes or changes that aim to improve product properties or functions, or decrease cost. The latter category is often connected with marketing, product management and customer interface. Sources of corrective engineering change request are versatile, but manufacturability and poor assembly properties are good examples in this case. In standard production mode ECM must be systematic and have enough discipline, but in agile prototyping and ramp-up phase it is too bureaucratic. On the other hand the goal of these different phases of product development is different. In standard production ECM aims to guarantee fluent material flow, but in prototyping and ramp-up phase purpose is to transfer information and knowledge bidirectionally between engineering design, internal and external productization, standard production, and other product stakeholders. In all, existing new product development processes, and especially engineering change processes are too rigid. Therefore, with the strategic business goal in mind, it should be investigated how digital manufacturing could improve the agility of NPD projects and ECM, and how PLM could support them.

Categorization of case findings. The case company's product strategy is based on innovative product functions and properties such as rock crushing capacity, mobility, safety and environment friendliness. Therefore it is important to intro- 
duce new products fast and conquer market share before the competitors. This business dimension is built on time-to-market capabilities and possibility to build the first prototypes very quickly. When the new product proves to be a success at the market place, there is a demand for producing machines and reacting to changing customer requirements in short order in order to keep the customers happy. This business dimension is linked to time-to-serial production and ability to rampup the serial production fast. In the partially configurable variant production mode this may be challenging. However, finally the business dimension of time-to-profit will determine in the long run how successful the product or more precisely the product development is. The products should meet their target cost as fast as possible. Therefore, it is important to link all these business dimensions from marketing and product management, to product design and development and finally to standard production. However, there should be a reasonable balance between those dimensions. Nevertheless, the strategic drivers of NPD projects may be emphasized differently in the product portfolio, i.e. is the time-to-market or cost more dominant. This research proposes categorizing the NPD projects and engineering change management based on those dimensions (Figure 1). This raises new questions: how does digital manufacturing benefit and impact NPD projects, and how should PLM support DM and change management?

In Figure 1 the case results are categorized in the dimensions of internal and external customers, new product development and standard production, corrective changes and betterment, physical and virtual product.

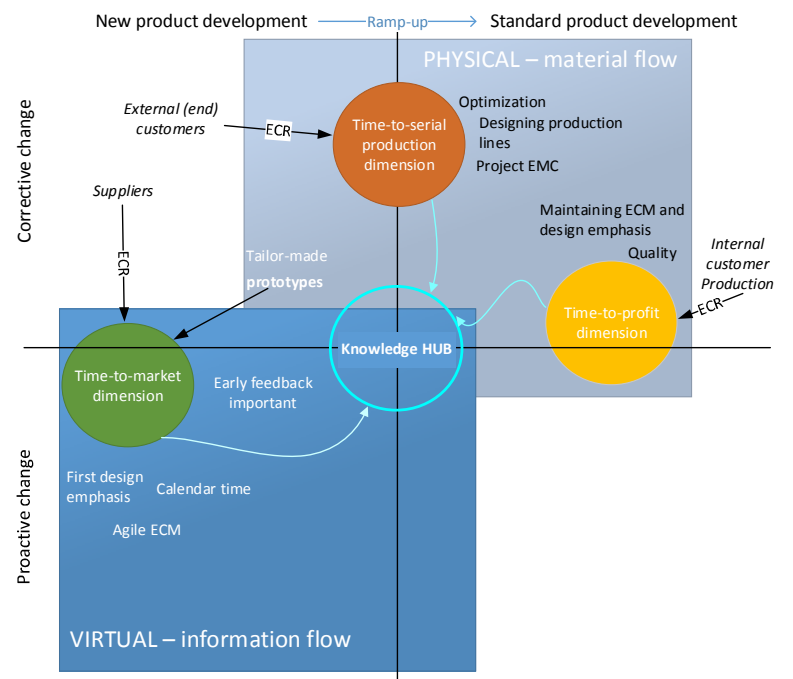

Figure 1. Structuring the dimensions of NPD and the role of virtual and physical product. The ramp-up phase and DM is seen as a knowledge HUB. 


\section{Discussion on the findings and PLM development targets}

From the process viewpoint, future PLM should integrate all product lifecycle stakeholders and related processes within early lifecycle stages [11, 12]. However, [11] and [12] argue that in practice product data management is still focused on managing conventional product data (e.g. BOM), because relevant PLM processes and information models are lacking in industry. Furthermore, our research indicates that PLM models should be more dynamic and configurable for different type of industries and business. Actually, our case study shows that PLM should be dynamic inside a new product development project and product launch. On the other hand, re-design of NPD, and launching new products in standard production line causes pressure to change the whole engineering design paradigm. DM is proposed to enable concurrent development of production and the product itself. However, the design maturity and the product structure should evolve so that it supports planning and evaluation of product assembly and other product life processes.

Productization, i.e. the processes for preparation of new products for market (external) and for standard production (internal) can be seen as a knowledge hub that should be better utilized in new product development and product knowledge management. It should be considered how the product knowledge can be best transferred to production, and also how the knowledge from production and other product stakeholders could be better transferred upstream to engineering design and product management. The recognized development targets of PLM capabilities in order to improve the knowledge transfer and change management will be discussed in the chapters following

Dominant business dimensions and project categories. It was reasoned that business goals lead to different dominant dimensions in NPD projects. On the other hand NPD project are different depending on the developed product and other issues. The dominant dimensions (time-to-market, time-to-serial production, timeto-profit) and project types should be balanced. Design of dedicated processes that are supported by DM and PLM is seen as a potential approach for reaching the balance. The chapter following discusses the dimensions.

In time-to-market dimension, it is essential to build the first prototypes fast and get early feedback from suppliers and key customers. The prototypes are "tailor-made", thus requiring good capabilities from the assembly workers and trusted suppliers that manufacture the components and sub-assemblies for the prototypes. Engineering design is optimized for producing the first prototype fast, but the emphasis is on product functions and properties, e.g. strength. However, it is critical to produce drawings early so that parts can be ordered from suppliers. Calendar time is dominant and engineering changes must be agile. ECRs are typically rooted from part manufacturability and fatigue of prototypes. DM enables evaluation of product structure before the physical prototype exists, and catching the most critical flaws. The process should be more based on 3D-models, not on drawings and documentation; including purchasing. 
In the time-to-serial production dimension, it is essential to deliver products to customers in time. Simultaneously the new product is prepared for standard production, i.e. productized internally. This means designing the production line, processes, material flows, tools and work tasks. Engineering design is making mainly corrective changes, but also some improving changes based on customer feedback. In this dimension it is also important to learn from the prototypes and customer feedback, test different product configurations and variants, produce assembly drawings and instructions, and plan the assembly tasks and material flows. In this phase suppliers often change from prototype part manufacturers to standard suppliers, and production may be launched globally. All product configurations cannot be tested with a physical prototype, which may lead to large amount of engineering change requests in standard production. DM enables testing many product configurations before physical production, evaluation of engineering changes without confusion of production line, and evaluation of production structure, work tasks, and material flow before physical production. However, this requires product structure and processes that support digital manufacturing including individual machine baseline structures. From assembly viewpoint, it is essential to populate the complete digital product structure early.

In the time-to-profit dimension it is still essential to maintain reliability with the customer deliveries, but simultaneously optimize the production and reduce the assembly hours in order to meet the target cost of the product type. Any product related problem may confuse the production line. Engineering design emphasis is on quality and maintaining fluent material flow. Communication for internal and external stakeholders (suppliers) is very important. DM enables communication and evaluation of engineering changes proactively as well as transferring product knowledge between engineering design, productization and standard production. Frontloaded NPD project should save corrective engineering change requests in this phase, thus meeting the target assembly hours and cost earlier.

Demands for PLM capabilities. The above mentioned NPD dimensions need different PLM capabilities. The dominant NPD dimension requires categorization of NPD projects. Therefore, there should be a possibility to choose different PLM configurations for different NPD project categories, or to change dynamically to another dominant dimension. A three class categorization was proposed in a case company is based on the dimensions between one-off delivery projects, and development of standard products. However, this categorization might be appropriate for selecting PLM configuration because prototyping phase can be juxtaposed with a one-off project, and development of standard product with time-to-serial production or time-to-profit dominant dimension. From the product and project management viewpoint NPD projects include for instance following dimensions: sales, project, engineering, procurement, and manufacturing. On the other hand, digital manufacturing and better utilization of 3D data was recognized as a potential means for improving productivity of NPD from business viewpoint. Engineering changes are related to product structure. Therefore product structure is in the centre of development targets, and PLM is the place where product structures should be managed. In NPD, ECRs are rooted from testing product functionality 
and strength, but also from assembly. Engineering design produces and modifies the product structure based on ECRs.

From the design engineer's point of view (Figure 2), the project may be $92 \%$ complete when only bolts, nuts, connectors etc. are missing from the structure. However, from assembly worker's point of view, the product is far from complete - without this information the product is impossible to build. As the bolts, nuts and connectors comprise significant percent of individual parts, this may mean that actually $80 \%$ of items are still missing from the structure - and therefore, from assembly and production planning point of view the model is only $20 \%$ complete. On the other hand, in case of assembly review, design calculations and analyses are less important - given that the actual product works and is safe. Therefore in assembly review it would be more important to have the best available mock-up of each component with relatively realistic dimensions. This also means that from assembly point of view, a product could be complete even when large proportion of design calculations and analysis are still incomplete. Thus, re-thinking the design process - producing and managing $3 \mathrm{D}$ in the product structure frame is needed.

One root cause for many communication- and knowledge-sharing defects is non-integrated PLM architecture which is created around functional organisations without compatible information models [13]. However, DM is a dimension of PLM that definitely requires and enables an integrated approach. [14] have proposed a central product structure model as an organisational and temporal hub and information backbone in concurrent engineering design and development, and in particular for frontloaded early project phases. DM could help in integration between designers and production department, because it provides a methodology and tools for transforming engineering structures to production structure including the realistic simulation of manufacturing [15]. Thus, parallel product structures are required because the engineering structure (EBOM) in EDM does not optimally serve production and other lifecycle stages. However, traditionally the EBOM is in engineering data management (EDM), assembly structure of production $(\mathrm{MBOM})$ is in PDM, and the assembly routing is in ERP.

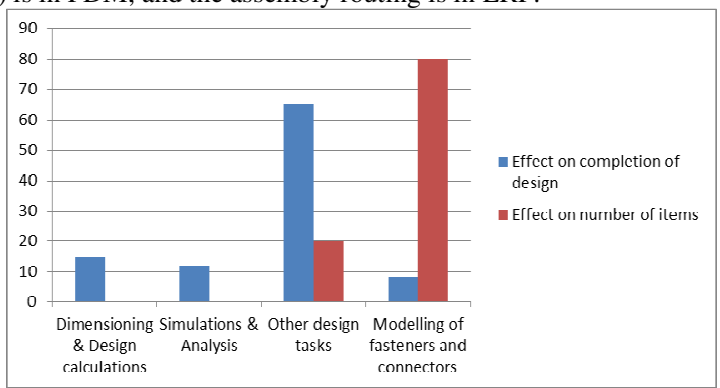

Figure 2. An example of design-related tasks and their effect on completion of design and number of items. 
Therefore, this information cannot be used in NPD, at least not at the beginning of an NPD project. When DM is also used for productization aspect, an appropriate virtual prototype (VP) structure is needed together with the required functionality. The VP structure is different from the hierarchical product design structure (EBOM), which is mostly built based on product functions. It is also different from the actual (physical) assembly structure (MBOM), because it is a simplified and restricted model for a certain purpose. Additionally, the VP structure should support the design process and design maturity in the embodiment design phase.

The created knowledge should be captured in a PLM system during the product development and lifecycle. Saving and managing such knowledge in a PLM system requires a mature and rich information model. However, the backward propagation of information from virtual prototyping, for instance from a virtual design review meeting to product data management is still a problem [16]. A VP "as-built" baseline structure is proposed to be the frame where information and knowledge e.g. from design reviews can be related to. This information and knowledge typically includes engineering change requests and arguments, ergonomics analysis reports, free comments and development proposals, virtual prototype configurations, meeting notes, video- and audio-recordings. Utilization of the PLM backbone for virtual prototyping requires a dedicated VP data model with an interface to workflow support, revision control, update management, access rights control, collaboration and conferencing [17].

Figure 3 aims to illustrate the idea of using DM and the digital product structure as a means for transferring ECR based knowledge from engineering design, to prototyping, ramp-up, and finally to standard production. Furthermore, the knowledge could be fed back as requirements to next generation NPD projects and product improvements.

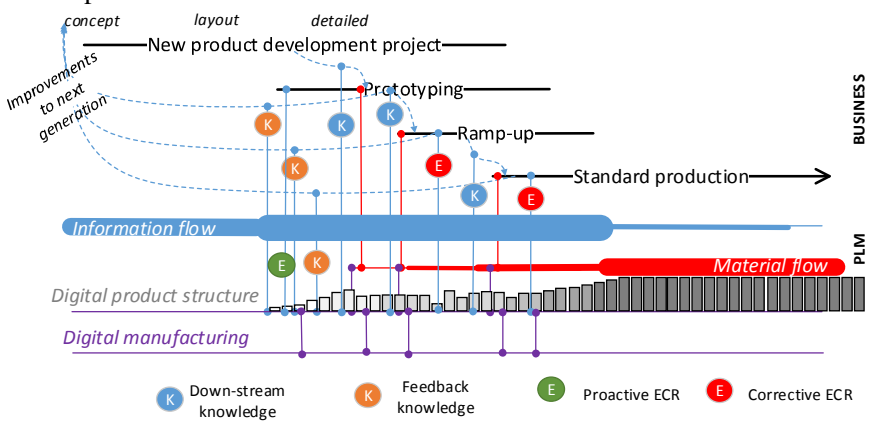

Figure 3 PLM model - Relations between engineering change requests, nowledge capture, information and material flow, and product structure.

As discussed before, the dominant dimension is different in different phases of the product process. Therefore, also PLM workflows that support frontloaded production of product structure and agile ECM in early NPD, integrated product and 
production system design in ramp-up phase, and ECM that guarantees good quality and material flow in standard production, are required. Besides the different nature of dominant dimensions and processes, also the configuration of value networks changes during and between the NPD project and standard production. Therefore also Different PLM architecture configurations are needed including characteristics of organisations, roles, supply networks, capabilities, COTS vs. inhouse, standards, data management systems, etc.

\section{Conclusion}

This paper discusses preliminary industrial case study findings about the recognized benefits of digital manufacturing and development targets of PLM in ECM of new product development projects. It is proposed that the findings are valid in manufacturing industry where products are partially configurable and complicated variants and the NPD projects are dynamic.

It was reasoned how business goals may lead to different dominant dimensions (time-to-market, time-to-serial production, time-to-profit) in NPD projects. Therefore, there should be a possibility to choose different PLM configurations for different dominant dimensions, or to change dynamically to another dominant dimension.

Engineering changes are related to product structure. Therefore product structure is in the centre of development targets of PLM. The main capabilities that support ECM in different dominant dimensions were discussed:

- NPD process should be more based on 3D models and simulations (DM);

- DM demands a dynamic, configurable, and integrated PLM architecture and processes;

- This requires parallel product structures for design/engineering, productization, production, and other lifecycle stages;

- The virtual prototype requires a specific product structure,

- A virtual prototype baseline structure and rich information model is proposed as a means for product knowledge management

- Design/engineering process should be re-defined to support the above;

\section{Acknowledgements}

This research is part of Fimecc-Manu programme which is funded by Tekes and the participating parties. 


\section{References}

[1] Ameri, F., \& Dutta, D. (2005). Product Lifecycle Management: Closing the Knowledge Loops. Computer-Aided Design and Applications, 2(5), 577-590.

[2] Durmusoglu, S. S. (2009). The role of top management team's information technology (IT) infrastructure view on new product development: Conceptualizing IT infrastructure capability as a mediator. European Journal of Innovation Management, 12(3), 364-385.

[3] Gerritsen, B., Gielingh, W., Dankwort, W., \& Anderl, R. (2011). Frameworks and technologies for exchanging and sharing product life cycle knowledge. Computer-Aided Design, 43(5), 459-463.

[4] Zhang, Y., Gregory, M., \& Shi, Y. (2008). Global engineering networks (GEN): Drivers, evolution, configuration, performance and key patterns. Journal of Manufacturing Technology Management, 19(3), 299-314.

[5] Unger, D., \& Eppinger, S. (2011). Improving product development process design: a method for managing information flows, risks, and iterations. Journal of Engineering Design, 22(10), 689-699.

[6] Keizer, J. a., \& Halman, J. I. M. (2009). Risks in major innovation projects, a multiple case study within a world's leading company in the fast moving consumer goods. International Journal of Technology Management, 48(4), 499.

[7] Ovtcharova, J. G. (2010). Virtual engineering : principles, methods and applications. In Proceedings of DESIGN 2010 (pp. 1267-1274).

[8] Pulkkinen, A. (2007). Product Configuration in Projecting Company: The Meeting of Configurable Product Families and Sales- Delivery Process. Tampere University of Technology.

[9] Fleche, D., Bluntzer, J.-B., Mahdjoub, M., \& Sagot, J.-C. (2014). Proposition of new and complementary evaluation approach of collaborative tools in a product design process. In I. Horváth \& Z. Rusak (Eds.), Proceedings of TMCE 2014, Budapest, Hungary (pp. 1283-1294).

[10] Leino, S.-P., Anttila, J., Heikkilä, J., Aaltonen, J., \& Helin, K. (2012). PLM Impact Analysis Model - PIA. In PLM 12 Conference Montreal, Canada, 9th-11th July (pp. 503-513)

[11]Abramovici, M. (2007). Future Trends in Product Lifecycle Management ( PLM ). In The future of product development, Proceedings of 17th CIRP Design Conference (pp. 665-674).

[12] Srinivasan, V. (2011). An integration framework for product lifecycle management. Computer-Aided Design, 43(5), 464-478.

| [13] Leino, S.-P., \& Pulkkinen, A. (2012). Design for human - virtual engineering is a media for knowledge transfer. In Proceedings of DESIGNN 2012, Dubrovnik - Croatia, (pp. 1507-1514).

[14] Kissel, M., Bradford, N., Kreimeyer, M., \& Lindemann, U. (2012). Product structure management as the backbone of engineering design: exploration of a reference model. In Proceedings of DESIGN 2012, Dubrovnik - Croatia, (pp.1709-1718).

[15] Lee, C., Leem, C. S., \& Hwang, I. (2011). PDM and ERP integration methodology using digital manufacturing to support global manufacturing. The International Journal of Advanced manufacturing technology, 53, 399-409.

| [16] Di Gironimo, G., Lanzotti, A., \& Tarallo, A. (2014). A virtual reality framework for the design review of complex industrial assemblies: case study on the interiors of superjet 100 aircraft. In I. Horváth \& Z. Rusak (Eds.), Proceedings of TMCE 2014, May 19-23, 2014, Budapest, Hungary (pp. 1553-1560)

[17] Rehfeld, I. (2010). Virtual Reality as an Integral Part of Product Lifecycle Management (PLM). In Joint Virtual Reality Conference of EGVE-ICAT - EuroVR

Formatted: German (Austria)

Formatted: German (Austria)

Formatted: English (United Kingdom) 